\title{
Upregulation of fascin-1 is involved in HIF-1 $\alpha$-dependent invasion and migration of hypopharyngeal squamous cell carcinoma
}

\author{
MINGQIANG BU ${ }^{1,2^{*}}$, XIANFANG LIU ${ }^{1,3,4^{*}}$, XIUXIU LIU ${ }^{1,3,4}$ and WEI XU $\mathrm{U}^{1,3,4}$ \\ ${ }^{1}$ Department of Otorhinolaryngology Head and Neck Surgery, Shandong Provincial ENT Hospital, \\ Shandong Provincial ENT Hospital Affiliated to Shandong University, Jinan, Shandong 250021; \\ ${ }^{2}$ Department of Otorhinolaryngology Head and Neck Surgery, Tengzhou Central People's Hospital, Tengzhou, \\ Shandong 277500; ${ }^{3}$ Key Laboratory of Otorhinolaryngology, National Health Commission (Shandong University), \\ Jinan, Shandong 250012; ${ }^{4}$ Shandong Provincial Key Laboratory of Otology, Jinan, Shandong 250022, P.R. China
}

Received November 27, 2018; Accepted June 6, 2019

DOI: 10.3892/ijo.2019.4827

\begin{abstract}
Fascin-1 is an actin-bundling protein, which specifically interacts with F-actin to form parallel actin bundles, and participates in the regulation of cell adhesion, interactions and migration. However, the expression and regulatory mechanisms of fascin-1 in hypopharyngeal squamous cell carcinoma (HSCC) remain poorly understood. The present study investigated the effects and underlying molecular mechanism of fascin-1 on the invasion and metastasis of HSCC. The results demonstrated that fascin-1 was overexpressed and correlated with lymph node metastasis and tumor-node-metastasis stage in HSCC tissues. Further in vitro study revealed that fascin-1 promoted cell morphology polarization to increase the motility of $\mathrm{FaDu}$ cells. In addition, fascin-1 significantly promoted the migration and invasion of FaDu cells. At the molecular level, fascin-1 promoted cell invasion and migration by upregulating matrix metalloproteinase-2 (MMP-2) expression in FaDu cells. Immunohistochemical analysis revealed that a correlation existed between hypoxia inducible factor (HIF)-1 $\alpha$ and fascin-1 expression in the HSCC tissues. Furthermore, the results from a cobalt chloride-induced hypoxia model demonstrated that fascin-1 may be upregulated by HIF-1 $\alpha$ in FaDu cells. Further analysis revealed that fascin-1 knockdown significantly decreased the invasion of cells under hypoxia and partially reversed hypoxia-induced MMP-2 expression under hypoxia in $\mathrm{FaDu}$ cells. In conclusion, fascin-1 was upregulated by HIF- $1 \alpha$, and promoted the invasion and migration of HSCC
\end{abstract}

Correspondence to: Dr Wei Xu, Department of Otorhinolaryngology Head and Neck Surgery, Shandong Provincial ENT Hospital, Shandong Provincial ENT Hospital Affiliated to Shandong University, 4 West Duanxing Road, Jinan, Shandong 250021, P.R. China E-mail: xuwhns@126.com

*Contributed equally

Key words: fascin-1, hypoxia inducible factor-1 $\alpha$, cobalt chloride, invasion, metastasis cells; therefore, fascin-1 may provide a potential target for the treatment of invasion and metastasis in HSCC.

\section{Introduction}

Hypopharyngeal squamous cell carcinoma (HSCC) is a common type of head and neck cancer, which has a poor prognosis and a 5-year survival rate of $25-40 \%$ (1-3). The majority of patients with HSCC are usually asymptomatic at the early stages and are diagnosed at the advanced stage $(4,5)$. Metastasis remains a leading cause of HSCC-associated mortality, despite marked improvements in the clinical comprehensive treatment of this malignancy $(6,7)$. Therefore, the underlying mechanisms that regulate tumor invasion and metastasis should be explored to develop novel strategies to treat HSCC.

Fascin-1 is a 55-kDa globular actin-bundling protein, which specifically interacts with F-actin to form parallel actin bundles, and participates in the regulation of cell adhesion, interactions and migration $(8,9)$. Fascin-1 expression in normal tissues is highly restricted to certain filopodium-rich cell types, including neurons and mature dendritic cells $(10,11)$, and fascin-1 expression is absent or low in normal epithelia (12). Conversely, fascin-1 is highly expressed in various epithelial neoplasms, including laryngeal squamous cell carcinoma (13), oral squamous cell carcinoma (14), and head and neck squamous cell carcinoma (15). In addition, fascin-1 overexpression is associated with cancer invasion and metastasis $(14,15)$.

Hypoxia is one of the most common types of microenvironmental stress in solid tumors, and is the result of overwhelming tumor growth and inadequate blood supply (16). Hypoxia has been reported to serve a key role in tumor metastasis $(17,18)$. Hypoxia-inducible factor-1 (HIF-1) is an important heterodimeric transcription factor composed of highly regulated HIF- $1 \alpha$ and constitutively expressed HIF- $1 \beta$ subunits. HIF- $1 \alpha$ is a key regulator of the cellular response to hypoxia, which has a vital role in HIF-1 transcriptional activity (19), and controls the expression of target genes associated with tumor invasion and metastasis (20). HIF-1 $\alpha$ promotes tumor invasion and metastasis in head and neck squamous cell carcinoma (21). A previous study also reported that HIF-1 $\alpha$ may promote invasion and metastasis by upregulating fascin expression in 
pancreatic ductal adenocarcinoma, and fascin is a direct target gene of HIF-1 $\alpha$ (22).

Fascin-1 expression in HSCC, and the potential roles of fascin-1 in the invasion and metastasis of HSCC remain unclear. Furthermore, the molecular mechanism underlying regulation of fascin- 1 by HIF- $1 \alpha$ under hypoxia in HSCC is still poorly understood. The present study aimed to investigate the effects of fascin-1 on the invasion and metastasis of HSCC, and to determine the molecular mechanism underlying regulation of fascin-1 by HIF-1 $\alpha$ under hypoxia in HSCC. The results demonstrated that fascin-1 was overexpressed in HSCC, and promoted the invasion and migration of HSCC. Furthermore, HIF-1 $\alpha$ promoted the invasion and migration of HSCC by upregulating fascin-1 expression.

\section{Materials and methods}

Reagents. Cobalt chloride hexahydrate $\left(\mathrm{CoCl}_{2} \cdot 6 \mathrm{H}_{2} \mathrm{O}\right.$; Sigma-Aldrich; Merck KGaA) was dissolved in deionized water to obtain a $200 \mathrm{mmol} / 1 \mathrm{CoCl}_{2}$ stock solution. The solution was further diluted with DMEM/F12 (Gibco; Thermo Fisher Scientific, Inc.) to achieve the desired concentration prior to use. Rhodamine phalloidin (Invitrogen; Thermo Fisher Scientific, Inc.) was dissolved in methanol to yield a stock concentration of $200 \mathrm{U} / \mathrm{ml}$. The solution was diluted with PBS to achieve the staining solution required for subsequent experiments. DAPI (cat. no. D1306) was purchased from Invitrogen; Thermo Fisher Scientific, Inc. Mouse anti-human fascin-1 (cat. no. TA807305), rabbit anti-human HIF-1 $\alpha$ (cat. no. ZA0552) and mouse anti-human $\beta$-actin (cat. no. TA-09) antibodies were purchased from Origene Technologies, Inc. Mouse anti-human HIF-1 $\alpha$ antibody (cat. no. 79233) was purchased from Cell Signaling Technology, Inc. Matrix metalloproteinase (MMP)-2 (cat. no. 10373-2-AP) and MMP-9 (cat. no. 10375-2-AP) antibodies were purchased from ProteinTech Group, Inc. E-cadherin antibody (cat. no. 610181) was purchased from BD Biosciences. Vimentin antibody (cat. no. ab92547) was purchased from Abcam.

Immunohistochemistry. HSCC tissues and adjacent normal tissues were obtained from 96 patients with HSCC at the Shandong Provincial ENT Hospital Affiliated to Shandong University between January 2010 and November 2014. Tissues were collected in accordance with the ethical approval and institutional guidelines of the Shandong Provincial ENT Hospital Affiliated to Shandong University. The tissue samples were fixed in $10 \%$ neutral buffered formalin at room temperature for $24 \mathrm{~h}$, embedded in paraffin, and cut into $5-\mu \mathrm{m}$ serial sections. Sections of each tissue sample were stained with hematoxylin and eosin for histological diagnosis. All diagnoses of primary HSCC were confirmed by at least two pathologists. No patient had received chemotherapy or radiotherapy prior to surgery. Written informed consent for tissue donation for research purposes was obtained from each patient prior to tissue collection, and the present study was approved by the Ethics Committee of Shandong University. Immunohistochemical staining was performed according to the manufacturer's protocol. The following primary antibodies were used: Mouse anti-human fascin-1 antibody (1:200) and rabbit anti-human HIF-1 $\alpha$ antibody (1:100). The sections were incubated with the primary antibodies overnight at $4^{\circ} \mathrm{C}$. Sections were then incubated with secondary biotinylated goat anti-rabbit immunoglobulin $\mathrm{G}$ antibody (IgG) (1:500; cat. no. SP-9001; OriGene Technologies, Inc.) or goat anti-mouse IgG antibody (1:500; cat. no. SP-9002; OriGene Technologies, Inc.) at $37^{\circ} \mathrm{C}$ for $15 \mathrm{~min}$. All histopathological images were captured under an Olympus BX53 microscope (Olympus Corporation). The results of immunohistochemical analysis were scored by two examiners who were blinded to the clinicopathological data. Cytoplasmic staining of cancer or paracarcinoma cells was regarded as positive fascin-1 or HIF-1 $\alpha$ immunostaining. Five random fields were observed under a light microscope at x200 magnification. For each visual field, 200 cells were counted (i.e., a total of 1,000 cells). Staining intensity was scored as follows: 0 , no staining; 1 , pale yellow staining; 2, yellowish-brown staining; and 3, brown staining. The extent of staining was scored as follows: $0,0 \%$ stained; 1, 1-25\% stained; 2, 26-50\% stained; and 3, 51-100\% stained. The final score was determined by multiplying the scores of intensity with the extent of staining. Therefore, the final score ranged between 0 and 9 , and final scores $\geq 3$ were considered positive expression.

Cell culture. The human FaDu cell line was purchased from the American Type Culture Collection. FaDu cells were cultured in DMEM/F12 (Gibco; Thermo Fisher Scientific, Inc.) containing $10 \%$ fetal bovine serum (FBS; Biological Industries) and incubated at $37^{\circ} \mathrm{C}$ in a humidified atmosphere consisting of $5 \% \mathrm{CO}_{2}$ and $95 \%$ air.

Silencing gene expression using small interfering RNA (siRNA). FaDu cells were plated at a density of $3 \times 10^{5}$ cells/well in 6-well plates. The siRNA sequences were as follows: Control siRNA duplexes, 5'-UUCUCCGAACGUGUCACGUTT-3'; fascin-1 siRNAduplexes,5'-GCAGCCTGAAGAAGAAGCA-3';HIF-1 $\alpha$ siRNA duplexes, 5'-CUAACUGGACACAGUGUGUTT-3'. The siRNAs were synthesized by Shanghai GenePharma Co., Ltd. Lipofectamine-RNA MAX Transfection Reagent (Invitrogen; Thermo Fisher Scientific, Inc.) was used to transfect cells with $1.25 \mu \mathrm{l}$ fascin-1 siRNA (20 $\mu \mathrm{mol} / 1), 1.25 \mu \mathrm{l} \mathrm{HIF-1} \alpha$ siRNA (20 $\mu \mathrm{mol} / \mathrm{l})$ or $1.25 \mu \mathrm{l}$ control siRNA $(20 \mu \mathrm{mol} / \mathrm{l})$ according to the manufacturer's protocol; cells were incubated with the siRNAs at $37^{\circ} \mathrm{C}$ for $48 \mathrm{~h}$. Gene silencing effects were evaluated by western blot analysis.

Plasmid transient transfection. FaDu cells were seeded at a density of $3 \times 10^{5}$ cells/well in 6-well plates and were transfected with $2.5 \mu \mathrm{g}$ GV144-fascin-1 plasmids (263 ng/ $\mu$ l; Shanghai GeneChem Co., Ltd.) or $2.5 \mu \mathrm{g}$ empty GV144 (control; $701 \mathrm{ng} / \mu \mathrm{l})$ using Lipofectamine-RNA LTX Transfection Reagent (Invitrogen; Thermo Fisher Scientific, Inc.) according to the manufacturer's protocol; cells were incubated with the plasmids at $37^{\circ} \mathrm{C}$ for $48 \mathrm{~h}$. The gene overexpressing effects of the plasmids were evaluated by western blot analysis.

Fluorescently labeled phalloidin staining. FaDu cells were seeded at a density of $4.2 \times 10^{4}$ cells/well in 48 -well plates containing coverslips. Cells cultured on a cover slip were fixed with $4 \%$ paraformaldehyde at room temperature for $10 \mathrm{~min}$ and stained with $5 \mu \mathrm{l}$ rhodamine phalloidin $(6.6 \mu \mathrm{mol} / \mathrm{l})$, which 
specifically binds to F-actin, at room temperature for $20 \mathrm{~min}$ according to the manufacturer's protocol. DAPI was used as a counterstain for $10 \mathrm{~min}$ at room temperature, for detection of the nuclei. Images were captured under a confocal microscope (TCS SPE; Leica Microsystems GmbH).

Establishment of hypoxia model. The hypoxia model was established by $\mathrm{CoCl}_{2}$ treatment, which is a well-known hypoxia mimetic. The hypoxia model was established as follows: FaDu cells were seeded at a density of $3 \times 10^{5}$ cells/well in 6-well plates. Subsequently, the cells were treated with $0,25,50$, 100,200 or $400 \mu \mathrm{mol} / 1$ of $\mathrm{CoCl}_{2}$ for 6,12 or $24 \mathrm{~h}$, and with $200 \mu \mathrm{mol} / 1 \mathrm{CoCl}_{2}$ for $0,3,6,12$ or $24 \mathrm{~h}$ at $37^{\circ} \mathrm{C}$. Alterations in HIF-1 $\alpha$ expression were evaluated by western blot analysis.

Cell Counting kit-8 (CCK-8) assay. Cell viability was detected using the CCK-8 assay (Beyotime Institute of Biotechnology). FaDu cells were seeded at a density of $3 \times 10^{3}$ cells/well in 96-well plates and incubated for $24 \mathrm{~h}$, after which the cells were treated with $0,25,50,100,200$ or $400 \mu \mathrm{mol} / 1 \mathrm{CoCl}_{2}$. CCK-8 assays were performed after treatment with $\mathrm{CoCl}_{2}$ for 6,12 or $24 \mathrm{~h}$ at $37^{\circ} \mathrm{C}$. Subsequently, $10 \mu \mathrm{l} \mathrm{CCK}-8$ solution was added to each well, and the cells were incubated for $2 \mathrm{~h}$ at $37^{\circ} \mathrm{C}$. Absorbance was measured at $450 \mathrm{~nm}$ using a microplate reader (BioTek Instruments, Inc.). The results were analyzed by SPSS 17.0 (SPSS, Inc.) and the graph was generated using GraphPad Prism 5 (GraphPad Software, Inc.).

Western blot analysis. The preparation of whole-cell protein lysates and western blot analysis were performed as previously described (23). Total proteins were extracted in lysis buffer and protein concentrations were measured using the protein bicinchoninic acid assay kit (Beyotime Institute of Biotechnology). Protein lysates $(40 \mu \mathrm{g})$ were separated by $10 \%$ SDS-PAGE and transferred to polyvinylidene difluoride membranes (EMD Millipore). Subsequently, the membranes were blocked with 5\% non-fat milk in Tris-buffered saline containing $0.05 \%$ Tween-20 for $1 \mathrm{~h}$ at room temperature, and were incubated at $4^{\circ} \mathrm{C}$ overnight with primary antibodies against fascin-1 (1:1,000), HIF-1 $\alpha$ (1:500), MMP-2 (1:1,000), MMP-9 (1:2,000), E-cadherin (1:6,0000), Vimentin $(1: 1,000)$ and $\beta$-actin $(1: 20,000)$. After washing with Tris-buffered saline containing $0.05 \%$ Tween-20, the membranes were incubated at room temperature for $1 \mathrm{~h}$ with horseradish peroxidase-linked secondary antibodies (1:10,000; goat anti-mouse IgG, cat. no. ZB-5305; goat anti-rabbit IgG, cat. no. ZB-5301; ZSGB-BIO). The protein bands were visualized using enhanced chemiluminescence reagent (cat. no. WBKLS0500; EMD Millipore) and analyzed by ImageJ software (version 1.37; National Institutes of Health).

Wound-healing assay. Cells were cultured in 6-well plates; once the cells reached $100 \%$ confluence, the medium containing $10 \%$ FBS was replaced with medium containing $1 \%$ FBS. A sterile $200-\mu$ l pipette tip was used to generate a wound in the cell layer. Wound healing was observed using an inverted light microscope after 0 and $24 \mathrm{~h}$, and images were captured using a Leica microscope image system (Leica Microsystems, Inc.). The fold change of wound healing was calculated using the following formula: Wound size at $24 \mathrm{~h} /$ wound size at $0 \mathrm{~h}$.
Wound size was measured using ImageJ software (version1.37; National Institutes of Health).

Transwell assays. Cell migration assays were performed using Transwell chambers (Costar; Corning, Inc.). The upper chamber of the Transwell system was filled with $250 \mu 1$ serum-free DMEM/F-12 containing $1 \times 10^{5}$ cells. Medium containing $20 \%$ FBS was added to the lower chamber as a chemoattractant, and the cells were incubated for $24 \mathrm{~h}$ at $37^{\circ} \mathrm{C}$. Migrating cells were fixed with $4 \%$ formaldehyde at room temperature for $15 \mathrm{~min}$ and stained with $0.1 \%$ crystal violet at room temperature for $25 \mathrm{~min}$. The number of cells that migrated onto the lower side of the membrane was determined using a light microscope (magnification, x100). Cell invasion assays were performed in the same manner as the cell migration assays; however, the Transwell chambers were pre-coated with $21 \mu$ l Matrigel (BD Biosciences; $1 / 3$ diluted in DMEM/F12) for $30 \mathrm{~min}$ at $37^{\circ} \mathrm{C}$. Each experiment was performed in triplicate, and five random microscopic fields per well were analyzed.

Statistical analysis. Analyses were performed using SPSS 17.0 statistical analysis software (SPSS, Inc.). The difference in fascin-1 expression between the paracarcinoma and HSCC tissues was assessed using Wilcoxon rank sum test. The correlation between fascin-1 and clinicopathological parameters or HIF-1 $\alpha$ was assessed using the Spearman rank correlation coefficient test. The relationship between fascin-1 and overall survival rate was assessed using the Kaplan-Meier method and compared with the log-rank test. All experiments were performed in triplicate. Data are presented as the mean \pm SD. The statistical significance of differences between two groups was analyzed with Student's t-test. The statistical significance of differences between multiple groups was analyzed with one-way ANOVA followed by the least-significant difference post-hoc test. All P-values were two sided, and $\mathrm{P}<0.05$ was considered to indicate a statistically significant difference.

\section{Results}

Expression offascin-1 in HSCC tissues.Immunohistochemistry was performed to validate fascin-1 expression using a cohort of 96 patients with HSCC. The results demonstrated that fascin-1 was mainly localized in the cytoplasm and cell membrane of tumor cells (Fig. 1). Paracarcinoma tissues revealed weak or partly moderate fascin-1 staining restricted to the basal layers (Fig. 1D), whereas HSCC tissues revealed variable distribution and intensity of fascin-1 staining, and fascin-1 expression at the invasive front of the tumor was considerably stronger than in other regions (Fig. 1H). Fascin-1 positive expression in HSCC tissues was detected in $88.54 \%$ of cases, which was significantly higher than in paracarcinoma tissues (Table I).

The Spearman rank correlation coefficient test was used to determine the relationships between fascin-1 expression and the clinicopathological characteristics of patients with HSCC. As shown in Table II, fascin-1 expression was significantly correlated with lymph node metastasis $(\mathrm{P}<0.001)$ and the pathological tumor-node-metastasis (TNM) stage $(\mathrm{P}<0.001)(24)$. These data suggested that fascin-1 may serve a vital role in the invasion and metastasis of HSCC. 

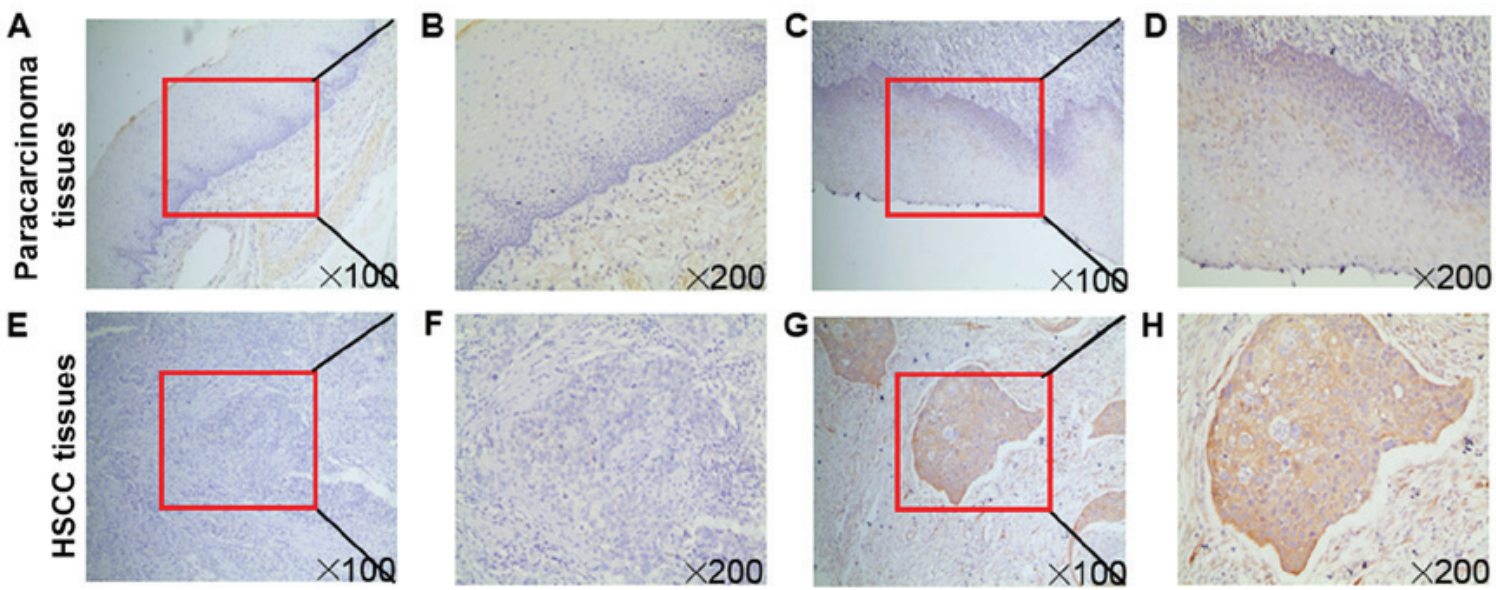

Figure 1. Immunochemical analysis of fascin-1 expression in HSCC. Fascin-1 protein expression in (A-D) paracarcinoma and (E-H) HSCC tissues. Higher magnification images of the boxed areas in (A), (C), (E) and (G) are shown in (B), (D), (F) and (H), respectively. (A, B, E and F) Negative expression of fascin-1 in paracarcinoma and HSCC tissues. (C, D, G and H) Positive expression of fascin-1 in paracarcinoma and HSCC tissues. (D) In the paracarcinoma tissues, fascin-1 revealed weak or partly moderate staining restricted to the basal layers. (H) In HSCC tissues, fascin-1 expression at the invasive front of the tumor was markedly stronger than in the other regions. Magnifications, x100 and x200. HSCC, hypopharyngeal squamous cell carcinoma.

Table I. Fascin-1 expression in paracarcinoma tissues and HSCC tissues.

\begin{tabular}{lclll}
\hline & & \multicolumn{2}{c}{ Fascin-1 expression } & \\
\cline { 3 - 4 } Tissue & Number & $\begin{array}{c}\text { Negative } \\
(\%)\end{array}$ & $\begin{array}{c}\text { Positive } \\
(\%)\end{array}$ & P-value \\
\hline Paracarcinoma & 96 & $72(75)$ & $24(25)$ & \\
HSCC & 96 & $11(11.46)$ & $85(88.54)$ & $<0.001$
\end{tabular}

HSCC, hypopharyngeal squamous cell carcinoma.

Furthermore, the relationship between fascin-1 and survival rate was analyzed; the results revealed that fascin-1 expression was not associated with 3 -year survival ( $\mathrm{P}=0.365$; Fig. $\mathrm{S} 1$ ). Therefore, fascin-1 may not serve an important role in HSCC prognosis.

Fascin-1 promotes the invasion and migration of FaDu cells. To determine the effects of fascin- 1 on FaDu cells, fascin-1 knockdown and overexpression were induced to reveal whether fascin-1 could modulate the efficiency of cell migration and invasion. Western blot analysis was used to determine the transfection efficiency of fascin-1 siRNA and expression plasmids in FaDu cells. The results demonstrated that fascin-1 expression was decreased with prolonged time post-transfection with fascin-1 siRNA (Fig. 2A), and the increase in fascin-1 expression peaked at $48 \mathrm{~h}$ post-transfection with fascin-1 expression plasmids in FaDu cells (Fig.2B). Therefore, cells were analysed $48 \mathrm{~h}$ post-transfection in subsequent experiments.

Fluorescently labeled phalloidin staining of F-actin was performed to observe alterations in cell morphology. The results demonstrated that the control cells exhibited a polarized shape with membrane protrusions; however, the fascin-1-silenced cells exhibited a more rounded morphology with fewer membrane protrusions (Fig. 2C). Cells in which fascin-1 was overexpressed exhibited a more polarized shape with more membrane protrusions (Fig. 2D). Filopodia were some of the membrane protrusions observed. These results suggested that fascin-1 may lead to changes in cell morphology, which could increase the motility and migratory ability of FaDu cells.

Wound-healing and Transwell assays were performed to further determine the effects of fascin-1 on cell migration and invasion. A wound-healing assay revealed that fascin-1-silenced cells migrated more slowly than the control cells (Fig. 3A), whereas fascin-1-overexpressed cells migrated more quickly than the control cells (Fig. 3B). A similar trend was observed in the migration assay. The results confirmed that the number of migrated cells was reduced in the fascin-1-silenced group compared with in the control group (Fig.3C), whereas the number of migrated cells was higher in the fascin-1-overexpressed group than in the control group (Fig. 3D). These results indicated that fascin-1 promoted the migration of FaDu cells. The results from the invasion assay revealed a reduction in the number of invasive cells in the fascin-1-silenced cells compared with in the control group (Fig. 3E); however, the number of invasive cells was increased in the fascin-1-overexpressed group compared with in the control group (Fig. 3F). Therefore, fascin-1 may promote the invasion of FaDu cells.

The expression of proteins associated with invasion, metastasis and epithelial-mesenchymal transition, including MMP-2, MMP-9, E-cadherin and vimentin were examined by western blotting to determine whether fascin-1 influenced cell invasion and migration at the molecular level. The results revealed that fascin-1 knockdown downregulated MMP-2 expression in $\mathrm{FaDu}$ cells (Fig. 4A), whereas fascin-1 overexpression upregulated MMP-2 expression in FaDu cells (Fig. 4B). However, no significant effect was observed on the other proteins(Fig. S2). These findings suggested that fascin-1 promoted invasion and migration of FaDu cells by upregulating MMP-2 .

Correlation between HIF-1 $\alpha$ and fascin-1 expression in HSCC tissues. The results of immunohistochemical analysis confirmed that fascin-1 expression colocalized with HIF-1 $\alpha$ expression in consecutive sections of HSCC tissues (Fig. 5). Fascin-1 expression was significantly correlated with HIF-1 $\alpha$ 
Table II. Correlation between fascin-1 expression and clinicopathological parameters of patients with hypopharyngeal squamous cell carcinoma.

Fascin-1 expression

\begin{tabular}{|c|c|c|c|c|c|}
\hline \multirow{2}{*}{ Parameter } & \multirow[b]{2}{*}{ Number } & & \multirow[b]{2}{*}{ rs } & \multirow[b]{2}{*}{ P-value } \\
\hline & & Negative (\%) & Positive (\%) & & \\
\hline \multicolumn{6}{|l|}{ Sex } \\
\hline Male & 91 & 10 & 81 & & \\
\hline Female & 5 & 1 & 4 & -0.063 & 0.543 \\
\hline \multicolumn{6}{|l|}{ Age (years) } \\
\hline$<60$ & 57 & 5 & 52 & & \\
\hline$\geq 60$ & 39 & 6 & 33 & -0.102 & 0.323 \\
\hline \multicolumn{6}{|l|}{ Differentiation } \\
\hline Well and moderate & 63 & 6 & 57 & & \\
\hline Poor & 33 & 5 & 28 & -0.084 & 0.416 \\
\hline \multicolumn{6}{|l|}{$\mathrm{T}$ classification } \\
\hline $\mathrm{T} 1-\mathrm{T} 2$ & 20 & 4 & 16 & & \\
\hline $\mathrm{T} 3-\mathrm{T} 4$ & 76 & 7 & 69 & 0.138 & 0.181 \\
\hline \multicolumn{6}{|l|}{ TNM stage } \\
\hline I-II & 5 & 3 & 2 & & \\
\hline III-IV & 91 & 8 & 83 & 0.357 & $<0.001$ \\
\hline \multicolumn{6}{|c|}{ Lymph node metastasis } \\
\hline Negative & 16 & 6 & 10 & & \\
\hline Positive & 80 & 5 & 75 & 0.366 & $<0.001$ \\
\hline \multicolumn{6}{|l|}{ Lung metastasis } \\
\hline Negative & 70 & 9 & 61 & & \\
\hline Positive & 26 & 2 & 24 & 0.072 & 0.485 \\
\hline
\end{tabular}

P-values were calculated by the Spearman rank correlation test. rs, Spearman's rank correlation coefficient.

Table III. Correlation between HIF-1 $\alpha$ and fascin-1 expression in hypopharyngeal squamous cell carcinoma.

\begin{tabular}{lccccc}
\hline & \multicolumn{2}{c}{ Fascin-1 expression } & & \\
\cline { 2 - 3 } $\begin{array}{l}\text { HIF-1 } \alpha \\
\text { expression }\end{array}$ & $\begin{array}{c}\text { Negative } \\
(\%)\end{array}$ & $\begin{array}{c}\text { Positive } \\
(\%)\end{array}$ & rs & P-value \\
\hline Negative & 7 & 20 & & \\
Positive & 4 & 65 & 0.284 & 0.005 \\
\hline
\end{tabular}

P-values were calculated by the Spearman rank correlation test. rs, Spearman's rank correlation coefficient.

expression in HSCC tissues (Table III). These results suggested that HIF-1 $\alpha$ may be involved in fascin-1 overexpression in HSCC tissues.

Upregulation of fascin-1 by HIF-1 $\alpha$ under hypoxia in FaDu cells. Previous results indicated that HIF-1 $\alpha$ may be involved in fascin-1 overexpression in HSCC tissues. Therefore, a hypoxia model was further established by $\mathrm{CoCl}_{2}$ treatment, which can upregulate HIF-1 $\alpha$ expression. The results demonstrated that the expression levels of HIF-1 $\alpha$ were increased in concentration-dependent and time-dependent manners after FaDu cells were treated with $\mathrm{CoCl}_{2}$ (Fig. 6A and B). CCK-8 assay revealed that cell viability was significantly decreased following treatment with $400 \mu \mathrm{mol} / 1 \mathrm{CoCl}_{2}$ (Fig. 6C). Therefore, $200 \mu \mathrm{mol} / 1 \mathrm{CoCl}_{2}$ was selected as the experimental concentration in subsequent studies.

To identify whether hypoxia promoted the expression of fascin-1 in FaDu cells, the cells were exposed to $200 \mu \mathrm{mol} / 1$ $\mathrm{CoCl}_{2}$ for $12 \mathrm{~h}$. Subsequently, western blot analysis was performed. The results demonstrated that, with the upregulation of HIF-1 $\alpha$, fascin-1 expression was considerably increased in $\mathrm{FaDu}$ cells under $\mathrm{CoCl}_{2}$-induced hypoxia compared with under normoxia (Fig. 6D). These data suggested that hypoxia could upregulate fascin-1 expression in FaDu cells.

HIF-1 $\alpha$ knockdown was performed to examine the role of HIF-1 $\alpha$ in regulating the expression of fascin-1 under hypoxia in FaDu cells. Since HIF-1 $\alpha$ protein undergoes rapid degradation under normoxic conditions, the expression levels of HIF-1 $\alpha$ were hardly detected in FaDu cells under normoxia. Therefore, the transfection efficiency of HIF-1 $\alpha$ siRNA could not be analyzed under normoxic conditions. Conversely, hypoxia promotes the stability of HIF-1 $\alpha$ via preventing its proteasomal degradation. Therefore, cells that underwent $\mathrm{CoCl}_{2}$-induced hypoxia for $48 \mathrm{~h}$ were transfected with HIF-1 $\alpha$ siRNA. As shown in Fig. 6E, the expression 
A
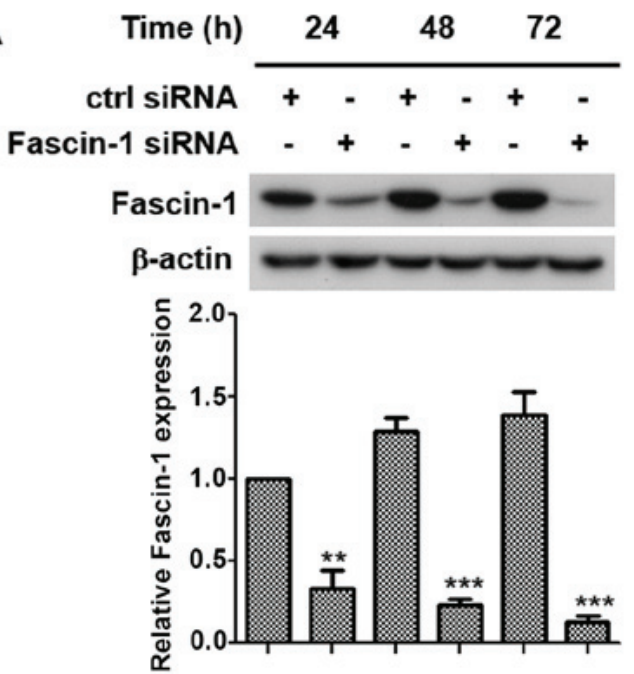

C
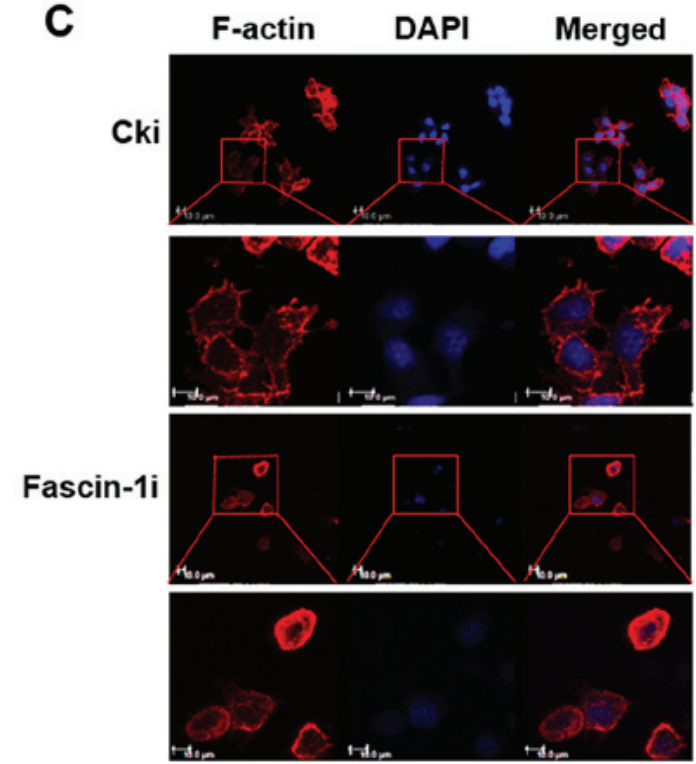

B

\begin{tabular}{|c|c|c|c|}
\hline Time (h) & 24 & 48 & 72 \\
\hline GV144 & + & + & + \\
\hline ascin-1 & - & - & $-\quad+$ \\
\hline
\end{tabular}

GV144-Fascin-1 - + - + - +
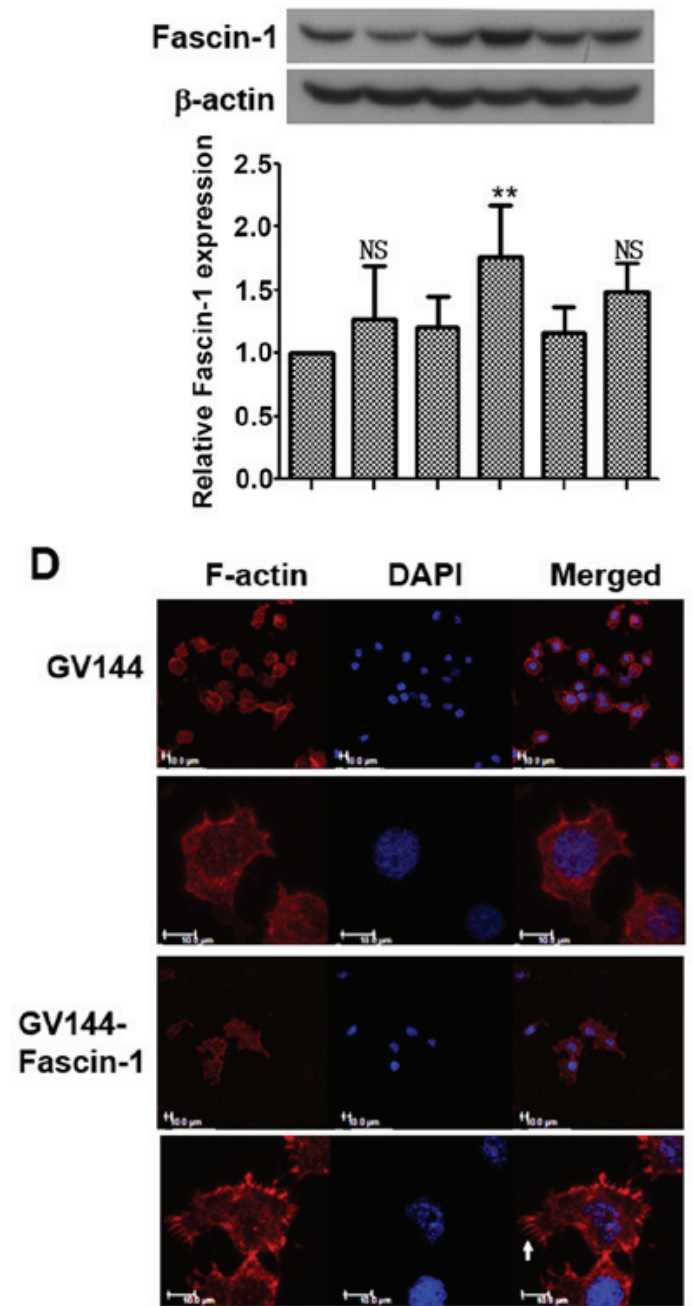

Figure 2. Transfection efficiency of fascin-1 and the effects of fascin-1 on the morphology of FaDu cells. Western blotting revealed that (A) fascin-1 siRNA downregulated fascin-1 expression in a time-dependent manner; fascin-1 expression was gradually downregulated with prolonged time in FaDu cells. Cki was used as a negative control. ${ }^{* *} \mathrm{P}<0.01 ;{ }^{* * * *} \mathrm{P}<0.001$ vs. Cki. (B) Fascin-1 expression plasmids increased fascin-1 expression in a time-dependent manner, and the increase in fascin-1 expression peaked at $48 \mathrm{~h}$. $\beta$-actin was used as an internal reference. ${ }^{* *} \mathrm{P}<0.01 ; \mathrm{NS}, \mathrm{P}>0.05 \mathrm{vs}$. GV144. Fluorescently labeled phalloidin staining revealed that (C) compared with control cells, the fascin-1-silenced cells exhibited a more rounded morphology with fewer membrane protrusions, such as filopodia. (D) Compared with the empty control vector cells, the fascin-1-overexpressed cells exhibited a more polarized shape with more membrane protrusions, such as filopodia. Scale bar, $10 \mu \mathrm{m}$. Arrows demonstrate filopodia bundles. Cells were counterstained with DAPI. Cki, control-siRNA; siRNA, small interfering RNA.

of $\mathrm{HIF}-1 \alpha$ under $\mathrm{CoCl}_{2}$-induced hypoxia was markedly reduced $48 \mathrm{~h}$ post-transfection with HIF-1 $\alpha$ siRNA. Further results demonstrated that HIF-1 $\alpha$ knockdown significantly downregulated the expression of fascin- 1 under $\mathrm{CoCl}_{2}$-induced hypoxia (Fig. 6E). These data suggested that hypoxia upregulated the expression of fascin-1 through HIF-1 $\alpha$, and HIF-1 $\alpha$ may serve a critical role in fascin-1 overexpression under hypoxia in FaDu cells.

Hypoxia promotes invasion and migration of FaDu cells by upregulating fascin-1 expression. An invasion assay and western blot analysis were performed to further determine whether hypoxia promoted cell invasion and migration through fascin-1. The invasion assay revealed that the number of invasive cells was significantly increased under hypoxia compared with under normoxia, whereas the number of invasive cells under hypoxia was reduced when fascin-1 was silenced (Fig. 7A). Western blot analysis revealed that hypoxia markedly increased the expression levels of MMP-2. However, fascin-1 knockdown partially reversed MMP-2 expression promoted by hypoxia in FaDu cells (Fig. 7B). These data suggested that hypoxia may promote the invasion and migration of FaDu cells by increasing fascin-1 expression.

\section{Discussion}

Tumor invasion and metastasis are complex processes. The acquisition of spindle-like morphology by reorganization of the cytoskeleton to enhance motility is regarded as an important step in tumor invasion and metastasis $(25,26)$. Another key step in tumor invasion and metastasis is degradation of the 
A
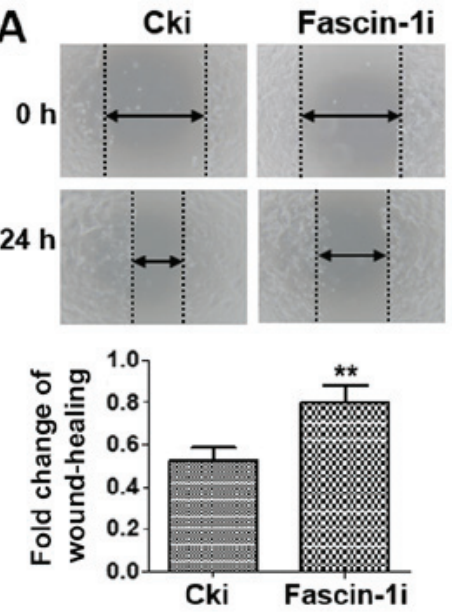

B GV144 GV144-Fascin-1
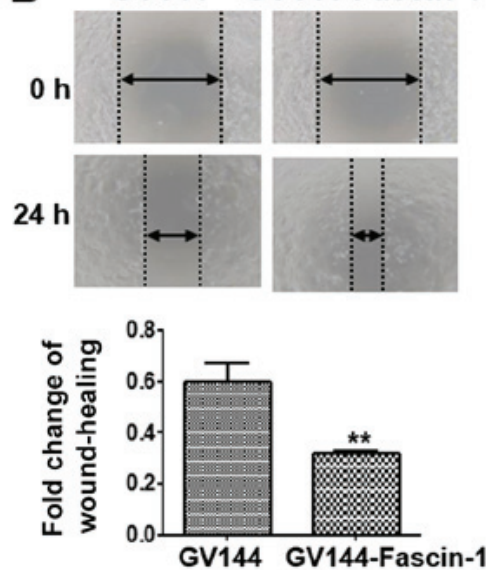

C
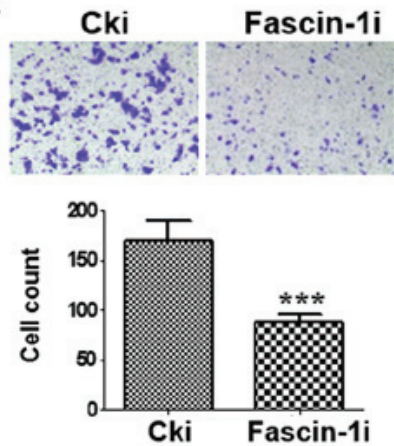

E
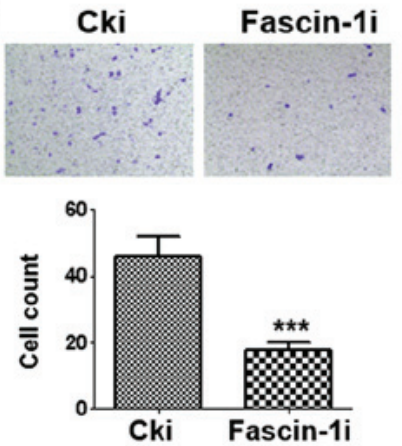

D
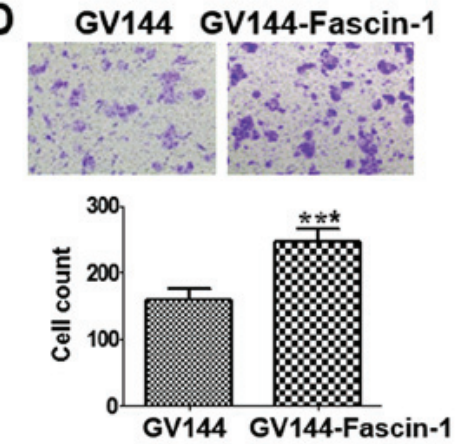

F GV144 GV144-Fascin-1
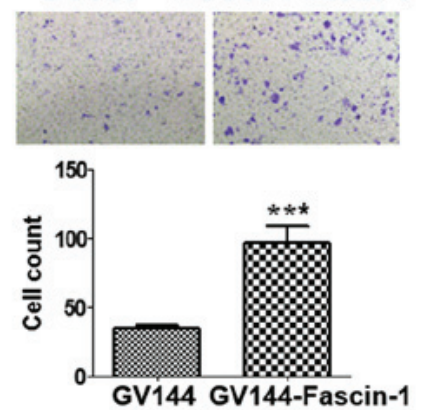

Figure 3. Effect of fascin-1 on cell migration and invasion in FaDu cells. Wound-healing assay revealed that (A) fascin-1-silenced FaDu cells migrated more slowly than the control cells; whereas (B) fascin-1-overexpressed FaDu cells migrated more quickly compared with the control cells (magnification, x100). Graphs show the fold change of wound healing margin at $24 \mathrm{~h}$, compared with the wound at $0 \mathrm{~h}$. Data are presented as the mean \pm SD from three independent experiments. Migration assay demonstrated that (C) the number of migrated cells was obviously decreased in fascin-1-silenced group compared with the control group; whereas (D) the number of migrated cells was significantly increased in the fascin-1-overexpressed group compared with the control group. Invasion assay demonstrated that (E) the number of invasive cells was obviously decreased in the fascin-1-silenced group compared with the control group; whereas $(\mathrm{F})$ the number of invasive cells was significantly elevated in the fascin-1-overexpressed group compared with the control group. Magnification, $\mathrm{x} 100$. Data are presented as the mean $\pm \mathrm{SD} .{ }^{* * *} \mathrm{P}<0.01 ;{ }^{* * *} \mathrm{P}<0.001$ vs. Cki or GV144. Cki, control-siRNA.

extracellular matrix; this degradation is associated with MMPs, such as MMP-2 and MMP-9 (27,28).

Fascin-1 is a cytoskeletal protein, which is involved in regulating the cytoskeleton structure and formation of plasma membrane protrusions by crosslinking actin microfilaments into tight, parallel bundles (29). Alam et al (14) reported that fascin overexpression is significantly correlated with tumor stage, lymph node metastasis and reduced differentiation in oral squamous cell carcinoma. Papaspyrou et al (15) reported the fascin is overexpressed in tumor tissues and is associated with lymph node metastases; furthermore, it was demonstrated that this overexpression is significantly correlated with lymph node metastasis in head and neck squamous cell carcinoma. Zhao et al (30) reported that fascin-1 overexpression is significantly correlated with age groups, clinical stages and lymph node metastases in lung cancer. Consistent with these previous studies, the present data indicated that fascin-1 was overexpressed in HSCC tissues and was significantly correlated with lymph node metastasis and pathological TNM stage. Therefore, fascin-1 overexpression may promote invasion and metastasis in HSCC. In addition, according to epidemiological investigations, sex is significantly associated with the incidence of hypopharyngeal carcinoma worldwide $(31,32)$. Consistently, the 96 patients with HSCC enrolled in this study exhibited a skew with regards to sex (91 male and 5 female). However, there was no significant correlation between fascin-1 expression and sex. To obtain fairly accurate statistical data, larger samples containing more female patients are required for further study.

Previous studies have indicated that fascin-1 promotes the invasion and migration of carcinoma in vitro. Alam et al (14) reported that fascin overexpression alters cell morphology, and increases cell migration, invasion and MMP-2 activity in oral squamous cell carcinoma cells. Zhao et al (33) demonstrated that fascin-1 knockdown suppresses cell invasion and migration in non-small cell lung cancer. In the present study, a HSCC cell line was used to determine the specific function of fascin-1 in invasion and migration of HSCC. At present, the FaDu cell line is the only available hypopharyngeal carcinoma cell line; therefore, only this cell line was used to 

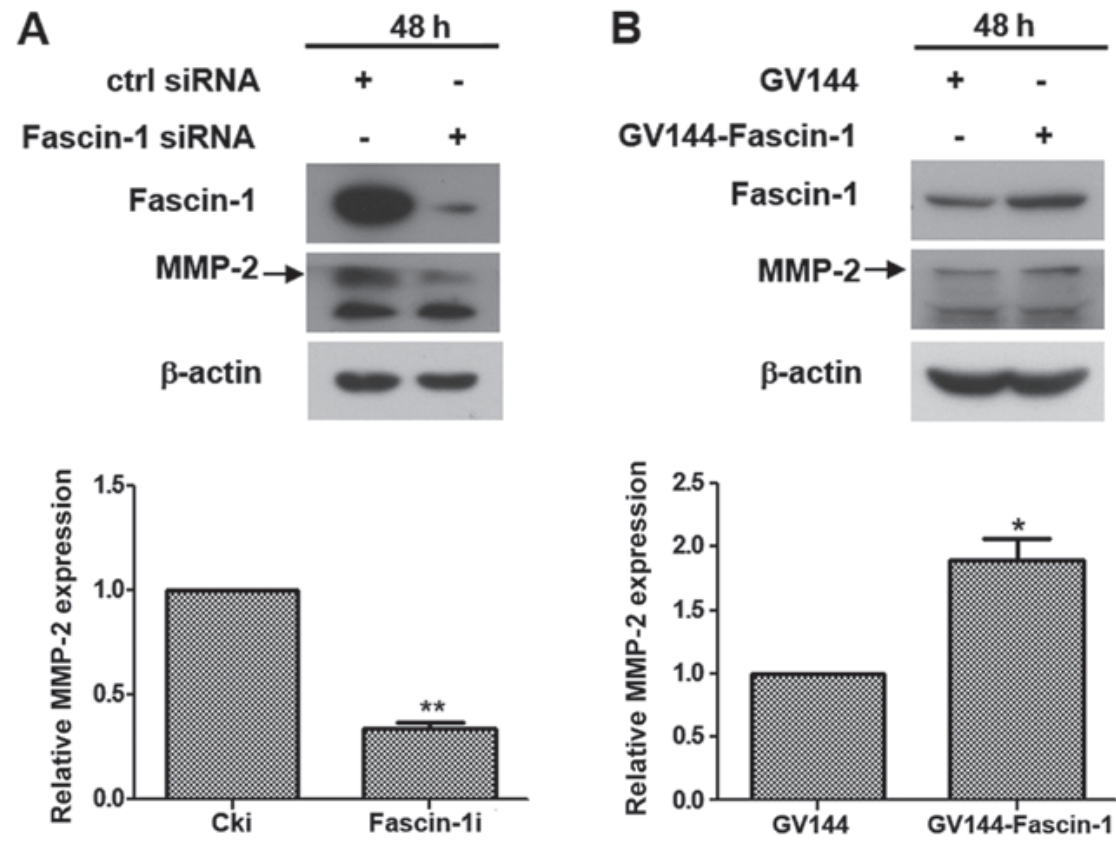

Figure 4. Fascin-1 promotes the invasion and migration of FaDu cells by upregulating MMP-2 expression. MMP-2 expression was examined by western blot analysis and semi-quantitative analysis revealed that (A) compared with in the control cells, MMP-2 expression was significantly downregulated in FaDu cells transfected with fascin-1 siRNA. (B) Compared in with the control cells, MMP-2 expression was significantly upregulated in FaDu cells transfected with fascin-1 expression plasmids. $\beta$-actin was used as an internal reference. MMP-2 expression was semi-quantified using ImageJ software. These experiments were performed in triplicate, and the bar graphs were obtained from three experiments. All values were normalized to cki or GV144 and paired Student's t-tests were used for analysis. Data are presented as the mean $\pm \mathrm{SD}$. ${ }^{*} \mathrm{P}<0.05,{ }^{* *} \mathrm{P}<0.01$ vs. Cki or GV144. Cki, control-siRNA; MMP-2, matrix metalloproteinase-2; siRNA, small interfering RNA.
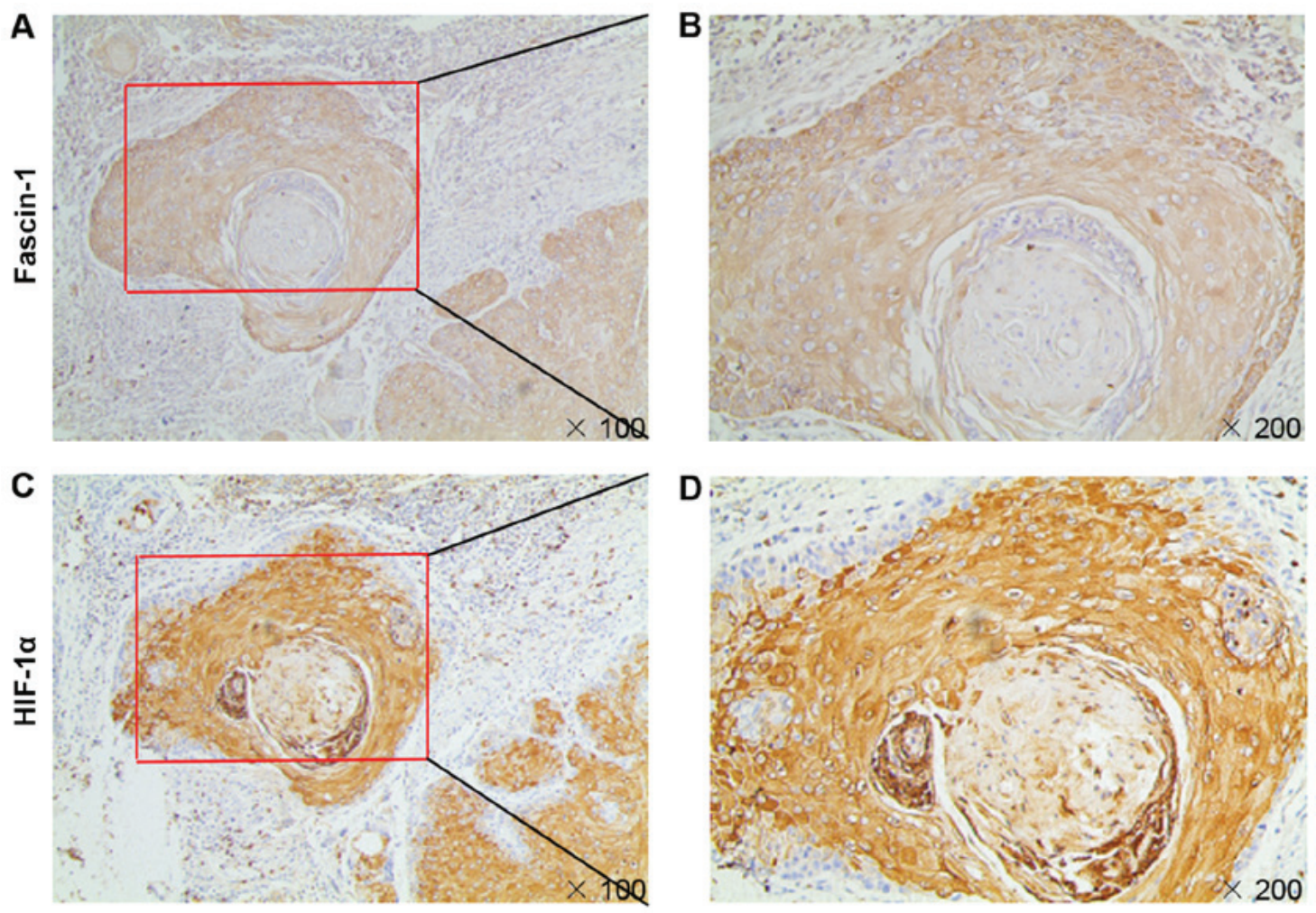

Figure 5. Colocalization of HIF-1 $\alpha$ and fascin-1 expression in hypopharyngeal squamous cell carcinoma. Immunohistochemical staining revealed the colocalization of HIF-1 $\alpha$ and fascin-1 expression in consecutive sections of HSCC tissues. Higher magnifications of the boxed areas in (A) and (C) are shown in (B) and (D), respectively. Magnifications, x100 and x200. HIF-1 $\alpha$, hypoxia inducible factor-1 $\alpha$.

conduct subsequent experiments, which may be a limitation to this study. To compensate for this, we are currently working on the construction of novel hypopharyngeal cancer cell lines using clinical specimen resources; however, this is yet to be 
A

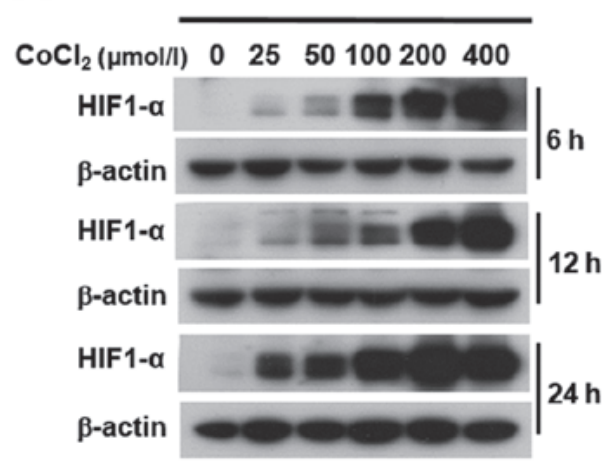

B

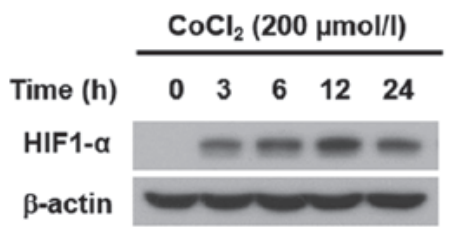

$24 \mathrm{~h}$
C
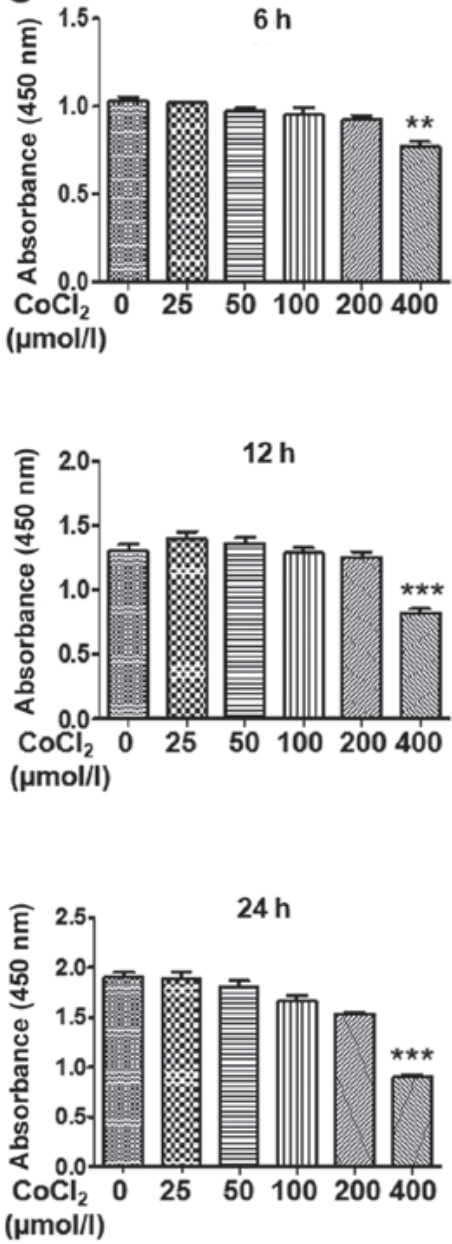

D

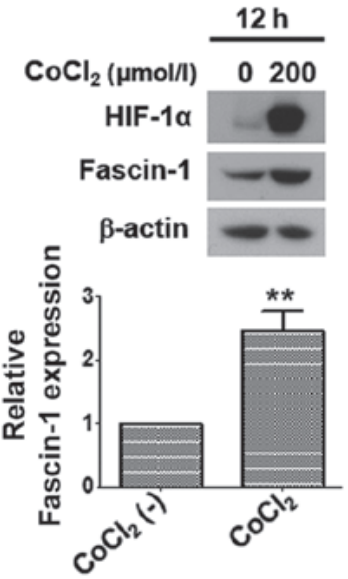

E

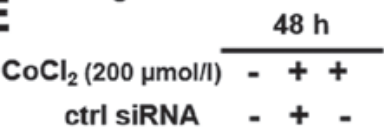

HIF-1a SIRNA --+

HIF-10

Fascin-1

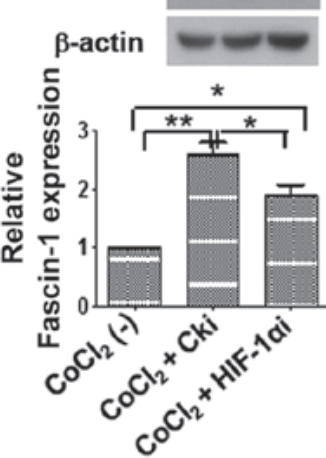

Figure 6. Effects of hypoxia induced by $\mathrm{CoCl}_{2}$ on HIF-1 $\alpha$ expression, and the upregulation of fascin-1 expression by HIF-1 $\alpha$ under hypoxia in FaDu cells (A) Expression of HIF-1 $\alpha$ was observed following treatment with $0,25,50,100,200$ or $400 \mu \mathrm{mol} / 1$ of $\mathrm{CoCl}_{2}$ for 6,12 or $24 \mathrm{~h}$ in FaDu cells. Western blotting revealed that HIF-1 $\alpha$ expression was upregulated in a concentration-dependent manner. $\beta$-actin was used as an internal reference. (B) Expression of HIF-1 $\alpha$ in FaDu cells was observed following treatment with $200 \mu \mathrm{mol} / 1 \mathrm{CoCl}_{2}$ for $0,3,6,12$ or $24 \mathrm{~h}$. Western blotting revealed that $\mathrm{CoCl}_{2}$ induced $\mathrm{HIF}-1 \alpha$ expression in a time-dependent manner, and HIF-1 $\alpha$ expression peaked at $12 \mathrm{~h}$ in FaDu cells. $\beta$-actin was used as an internal reference. (C) Viability of FaDu cells treated with $0,25,50,100,200$ or $400 \mu \mathrm{mol} / 1 \mathrm{CoCl}_{2}$ for 6,12 or $24 \mathrm{~h}$, as determined by Cell Counting kit- 8 assay. No significant difference was detected in cell viability at concentrations ranging between 0 and $200 \mu \mathrm{mol} / 1$. However, following treatment with $400 \mu \mathrm{mol} / 1 \mathrm{CoCl}_{2}$, cell viability was significantly decreased. ${ }^{* *} \mathrm{P}<0.01$, ${ }^{* * *} \mathrm{P}<0.001$ vs. $0 \mu \mathrm{mol} / \mathrm{l}$. Western blotting and semi-quantitative analysis revealed that (D) compared with under normoxia, hypoxia induced by treatment with $200 \mu \mathrm{mol} / 1 \mathrm{CoCl}_{2}$ for $12 \mathrm{~h}$ upregulated HIF-1 $\alpha$ and fascin-1 expression in FaDu cells. Student's t-test was used for analysis. (E) HIF-1 $\alpha$ knockdown reduced the expression of fascin-1 under hypoxia post-transfection with HIF-1 $\alpha$ siRNA for $48 \mathrm{~h}$ in FaDu cells. One-way ANOVA was used for analysis. $\beta$-actin was used as an internal reference. Protein expression was semi-quantified using ImageJ software, and the $\mathrm{CoCl}_{2}(-)$ group was set at 1 . Data are presented as the mean \pm SD. ${ }^{*} \mathrm{P}<0.05,{ }^{* *} \mathrm{P}<0.01 . \mathrm{CoCl}_{2}$, cobalt chloride; HIF-1 $\alpha$, hypoxia inducible factor- $1 \alpha$; siRNA, small interfering RNA.

successful. In future studies, we will consider using primary cells to conduct cell experiments. In the present study, consistent with previous studies $(14,33)$, the in vitro analyses revealed that fascin-1 led to cells with a more polarized shape and more membrane protrusions, such as filopodia, which increased the motility of FaDu cells. Further functional studies revealed that fascin-1 significantly promoted the migration and invasion of FaDu cells. Molecular mechanism studies indicated that fascin-1 upregulated the expression of MMP-2, which may be associated with the invasion and migration of $\mathrm{FaDu}$ cells. In summary, these data suggested that fascin-1 promoted cell invasion and migration in HSCC.

The present results also identified colocalization of HIF-1 $\alpha$ and fascin- 1 expression, and the correlation between HIF-1 $\alpha$ and fascin-1 expression was significant in HSCC specimens. Therefore, an underlying regulatory mechanism may exist between fascin-1 and HIF-1 $\alpha$. Zhao et al (22) also reported that fascin expression is colocalized with HIF- $1 \alpha$ and is significantly correlated with HIF-1 $\alpha$ expression in pancreatic ductal adenocarcinoma tissues. Therefore, the underlying regulatory mechanism between HIF-1 $\alpha$ and fascin-1 in HSCC should be established.

Hypoxia and $\mathrm{CoCl}_{2}$ increase HIF-1 $\alpha$ expression; $\mathrm{CoCl}_{2}$ can be used to stabilize HIF-1 $\alpha$ and mimic true hypoxic conditions, which activate HIF-1 $\alpha$ (34). In the present study, the $\mathrm{CoCl}_{2}$-induced chemical hypoxia model was established. Further studies revealed that $\mathrm{CoCl}_{2}$-induced hypoxia increased the expression of fascin-1. This result suggested that hypoxia increased fascin-1 expression in FaDu cells. A previous study demonstrated that HIF-1 $\alpha$ knockdown markedly downregulates the expression of fascin under true hypoxia $\left(1 \% \mathrm{O}_{2}\right)$, and fascin is a direct target gene of HIF-1 $\alpha$ (22). In line with this previous 
A

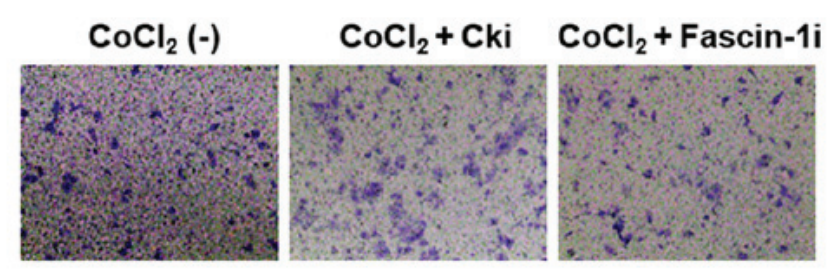

B

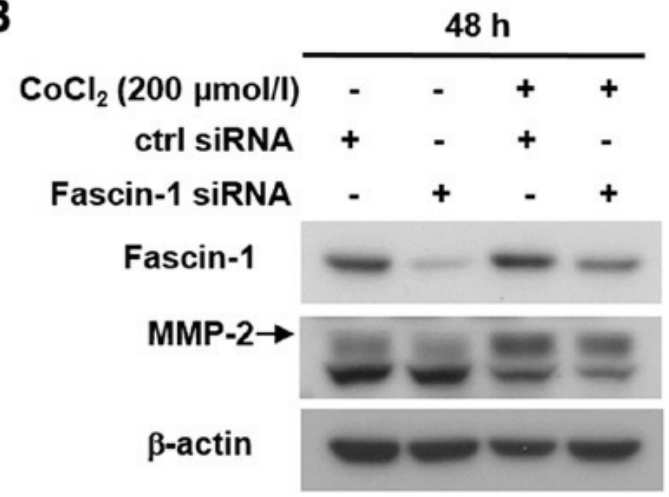

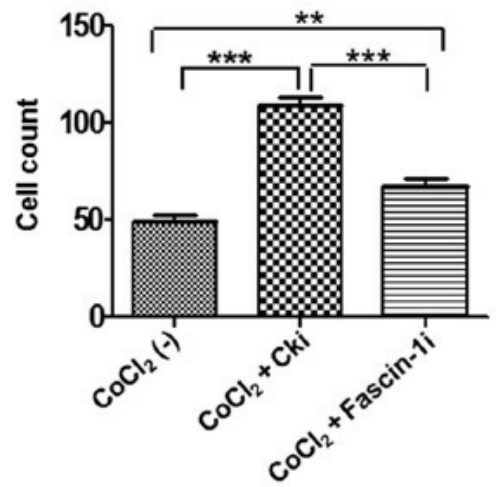

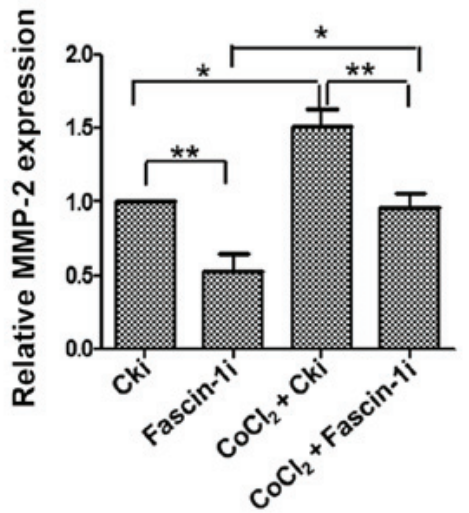

Figure 7. Hypoxia promotes the invasion and migration of FaDu cells by upregulating fascin-1 expression. (A) Invasion assay revealed that the number of invasive cells was increased under hypoxia $\left(200 \mu \mathrm{mol} / 1 \mathrm{CoCl}_{2}\right)$ compared with under normoxia. However, under hypoxia, the number of invasive cells was reduced in response to fascin-1 knockdown. Magnification, x100. (B) Western blot analysis demonstrated that hypoxia markedly increased the expression levels of MMP-2, whereas fascin-1 knockdown partially reversed MMP-2 expression promoted by hypoxia in FaDu cells. $\beta$-actin was used as an internal reference. MMP-2 expression was semi-quantified using ImageJ software. Data are presented as the mean $\pm \mathrm{SD}$. ${ }^{*} \mathrm{P}<0.05,{ }^{* *} \mathrm{P}<0.01,{ }^{* * *} \mathrm{P}<0.001 . \mathrm{CoCl}_{2}, \mathrm{cobalt}$ chloride; MMP-2, matrix metalloproteinase-2; siRNA, small interfering RNA.

report, our further studies revealed that HIF-1 $\alpha$ knockdown downregulated the expression of fascin-1 under $\mathrm{CoCl}_{2}$-induced hypoxia in FaDu cells. These results suggested that hypoxia elevated the expression of fascin-1 though HIF-1 $\alpha$ in FaDu cells, and HIF-1 $\alpha$, as a transcription factor, may upregulate fascin-1 expression.

Zhao et al (22) reported that hypoxia promotes the invasion and migration of pancreatic ductal adenocarcinoma by inducing fascin overexpression. The present invasion assay data revealed that $\mathrm{CoCl}_{2}$-induced hypoxia significantly promoted the invasion of $\mathrm{FaDu}$ cells, whereas fascin-1 knockdown partially decreased the invasion of FaDu cells under hypoxia. Furthermore, mechanistic studies indicated that fascin-1 knockdown partially reversed the MMP-2 overexpression promoted by HIF- $1 \alpha$ under $\mathrm{CoCl}_{2}$-induced hypoxia in FaDu cells. These results suggested that fascin-1 was involved in the HIF-1 $\alpha$-dependent invasion and migration of HSCC, and fascin-1 may serve a vital role in promoting cell invasion and migration under a hypoxic microenvironment in HSCC.

In conclusion, these results indicated that fascin-1 was overexpressed in HSCC, and was significantly associated with the invasion and metastasis of HSCC. Furthermore, the present data suggested that HIF-1 $\alpha$ may promote the invasion and migration of HSCC cells by upregulating fascin-1 expression. Several small-molecule inhibitors targeting fascin-1 have been reported to prevent tumor metastasis (35). Therefore, Fascin-1 may provide a potential target for the treatment of invasion and metastasis in HSCC.

\section{Acknowledgements}

Not applicable.

\section{Funding}

The present study was supported by grants from the National Natural Science Foundation of China (grant no. 81702679), the Natural Science Foundation of Shandong province (grant no. ZR2017BH060) and the Key Project of Shandong Provincial Programs for Research and Development (grant no. 2018GSF118225).

\section{Availability of data and materials}

The datasets used and/or analyzed during the current study are available from the corresponding author on reasonable request.

\section{Authors' contributions}

MB and XL contributed equally to this article. WX designed the experiments. MB wrote the paper and performed the experiments. XL performed the experiments and revised the paper. MB and XL were responsible for collecting all data and 
analyzed the data in the study. WX checked the manuscript. All authors have read and approved the final manuscript.

\section{Ethics approval and consent to participate}

The present study was approved by the ethics committee of Shandong University and written informed consent was obtained from patients prior to sample collection.

\section{Patient consent for publication}

Not applicable.

\section{Competing interests}

The authors declare that they have no competing interests.

\section{References}

1. Gooi Z, Fakhry C, Goldenberg D, Richmon J and Kiess AP; Education Committee of the American Head and Neck Society (AHNS): AHNS Series: Do you know your guidelines? Principles of radiation therapy for head and neck cancer: A review of the National Comprehensive Cancer Network guidelines. Head Neck 38: 987-992, 2016.

2. Lewis CM, Hessel AC, Roberts DB, Guo YZ, Holsinger FC, Ginsberg LE, El-Naggar AK and Weber RS: Prereferral head and neck cancer treatment: Compliance with national comprehensive cancer network treatment guidelines. Arch Otolaryngol Head Neck Surg 136: 1205-1211, 2010.

3. Wycliffe ND,Grover RS,KimPD and Simental AJr:Hypopharyngeal cancer. Top Magn Reson Imaging 18: 243-258, 2007.

4. Ge N, Lin HX, Xiao XS, Guo L, Xu HM, Wang X, Jin T, Cai XY, Liang Y, Hu WH, et al: Prognostic significance of Oct4 and Sox 2 expression in hypopharyngeal squamous cell carcinoma. J Transl Med 8: 94, 2010.

5. Kotwall C, Sako K, Razack MS, Rao U, Bakamjian V and Shedd DP: Metastatic patterns in squamous cell cancer of the head and neck. Am J Surg 154: 439-442, 1987.

6. Hui AB, Bruce JP, Alajez NM, Shi W, Yue S, Perez-Ordonez B, $\mathrm{Xu}$ W, O'Sullivan B, Waldron J, Cummings B, et al: Significance of dysregulated metadherin and microRNA-375 in head and neck cancer. Clin Cancer Res 17: 7539-7550, 2011.

7. Loberg RD, Bradley DA, Tomlins SA, Chinnaiyan AM and Pienta KJ: The lethal phenotype of cancer: The molecular basis of death due to malignancy. CA Cancer J Clin 57: 225-241, 2007.

8. Adams JC: Formation of stable microspikes containing actin and the $55 \mathrm{kDa}$ actin bundling protein, fascin, is a consequence of cell adhesion to thrombospondin-1: Implications for the anti-adhesive activities of thrombospondin-1. J Cell Sci 108: 1977-1990, 1995

9. Adams JC: Fascin protrusions in cell interactions. Trends Cardiovasc Med 14: 221-226, 2004.

10. Duh FM, Latif F, Weng Y, Geil L, Modi W, Stackhouse T, Matsumura F, Duan DR, Linehan WM, Lerman MI, et al: cDNA cloning and expression of the human homolog of the sea urchin fascin and Drosophila singed genes which encodes an actin-bundling protein. DNA Cell Biol 13: 821-827, 1994.

11. De Arcangelis A, Georges-Labouesse E and Adams JC: Expression of fascin-1, the gene encoding the actin-bundling protein fascin-1, during mouse embryogenesis. Gene Expr Patterns 4: 637-643, 2004

12. Zhang FR, Tao LH, Shen ZY, Lv Z, Xu LY and Li EM: Fascin expression in human embryonic, fetal, and normal adult tissue. J Histochem Cytochem 56: 193-199, 2008.

13. Zou J, Yang H, Chen F, Zhao H, Lin P, Zhang J, Ye H, Wang L and Liu S: Prognostic significance of fascin-1 and E-cadherin expression in laryngeal squamous cell carcinoma. Eur J Cancer Prev 19: 11-17, 2010.

14. Alam H, Bhate AV, Gangadaran P, Sawant SS, Salot S, Sehgal L, Dange PP, Chaukar DA, D'cruz AK, Kannanl S, et al: Fascin overexpression promotes neoplastic progression in oral squamous cell carcinoma. BMC Cancer 12: 32, 2012.
15. Papaspyrou K, Brochhausen C, Schmidtmann I, Fruth K, Gouveris H, Kirckpatrick J, Mann W and Brieger J: Fascin upregulation in primary head and neck squamous cell carcinoma is associated with lymphatic metastasis. Oncol Lett 7: 2041-2046, 2014.

16. Shay JE and Celeste Simon M: Hypoxia-inducible factors: Crosstalk between inflammation and metabolism. Semin Cell Dev Biol 23: 389-394, 2012.

17. Subarsky P and Hill RP: The hypoxic tumour microenvironment and metastatic progression. Clin Exp Metastasis 20: 237-250, 2003.

18. Gilkes DM, Semenza GL and Wirtz D: Hypoxia and the extracellular matrix: Drivers of tumour metastasis. Nat Rev Cancer 14: 430-439, 2014.

19. Semenza GL: Hydroxylation of HIF-1: Oxygen sensing at the molecular level. Physiology (Bethesda) 19: 176-182, 2004.

20. Brahimi-Horn MC, Bellot G and Pouysségur J: Hypoxia and energetic tumour metabolism. Curr Opin Genet Dev 21: 67-72, 2011.

21. Zhu G, Peng F, Gong W, She L, Wei M, Tan H, Chen C, Zhang D, Li G, Huang D, et al: Hypoxia promotes migration/invasion and glycolysis in head and neck squamous cell carcinoma via an HIF-1 $\alpha$-MTDH loop. Oncol Rep 38: 2893-2900, 2017.

22. Zhao X, Gao S, Ren H, Sun W, Zhang H, Sun J, Yang S and Hao J: Hypoxia-inducible factor-1 promotes pancreatic ductal adenocarcinoma invasion and metastasis by activating transcription of the actin-bundling protein fascin. Cancer Res 74: 2455-2464, 2014.

23. Liu X, Yue P, Zhou Z, Khuri FR and Sun SY: Death receptor regulation and celecoxib-induced apoptosis in human lung cancer cells. J Natl Cancer Inst 96: 1769-1780, 2004.

24. Edge SB, Byrd DR, Compton CC, Fritz AG, Greene FL and Trotti A (eds). AJCC Cancer Staging Manual. 7th edition. Springer, New York, NY, 2010.

25. Haynes J, Srivastava J, Madson N, Wittmann T and Barber DL: Dynamic actin remodeling during epithelial-mesenchymal transition depends on increased moesin expression. Mol Biol Cell 22: 4750-4764, 2011

26. Liu SC, Jen YM, Jiang SS, Chang JL, Hsiung CA, Wang CH and Juang JL: G(alpha)12-mediated pathway promotes invasiveness of nasopharyngeal carcinoma by modulating actin cytoskeleton reorganization. Cancer Res 69: 6122-6130, 2009.

27. Sato H, Kida Y, Mai M, Endo Y, Sasaki T, Tanaka J and Seiki M: Expression of genes encoding type IV collagen-degrading metalloproteinases and tissue inhibitors of metalloproteinases in various human tumor cells. Oncogene 7: 77-83, 1992.

28. Okazaki I and Inagaki Y: Novel strategies for hepatocellular carcinoma based on MMPs science. Anticancer Agents Med Chem 12: 753-763, 2012.

29. Edwards RA and Bryan J: Fascins, a family of actin bundling proteins. Cell Motil Cytoskeleton 32: 1-9, 1995

30. Zhao W, Gao J, Wu J, Liu QH, Wang ZG, Li HL and Xing LH: Expression of Fascin-1 on human lung cancer and paracarcinoma tissue and its relation to clinicopathological characteristics in patients with lung cancer. Onco Targets Ther 8: 2571-2576, 2015.

31. Zhang ZM, Tang PZ, Xu ZG, Li QH, Hu YH, Xu GZ, Gao L and Tu GY: Long-term results of different treatment modalities in 464 hypopharyngeal squamous-cell carcinoma patients. Zhonghua Zhong Liu Za Zhi 27: 48-51, 2005 (In Chinese).

32. Hoffman HT, Karnell LH, Shah JP, Ariyan S, Brown GS, Fee WE, Glass AG, Goepfert H, Ossoff RH and Fremgen AM: Hypopharyngeal cancer patient care evaluation. Laryngoscope 107: 1005-1017, 1997.

33. Zhao D, Zhang T, Hou XM and Ling XL: Knockdown of fascin-1 expression suppresses cell migration and invasion of non-small cell lung cancer by regulating the MAPK pathway. Biochem Biophys Res Commun 497: 694-699, 2018.

34. Huang BW, Miyazawa M and Tsuji Y: Distinct regulatory mechanisms of the human ferritin gene by hypoxia and hypoxia mimetic cobalt chloride at the transcriptional and post-transcriptional levels. Cell Signal 26: 2702-2709, 2014

35. Chen L, Yang S, Jakoncic J, Zhang JJ and Huang XY: Migrastatin analogues target fascin to block tumour metastasis. Nature 464: 1062-1066, 2010

This work is licensed under a Creative Commons Attribution-NonCommercial-NoDerivatives 4.0 International (CC BY-NC-ND 4.0) License. 